\title{
Influence of oak wood polyphenols on cysteine, homocysteine and glutathione total levels and PON1 activities in human adult volunteers - a pilot study
}

\author{
Zuzana Deáková1,2, Zuzana Országhová ${ }^{1}$, Lucia Andrezálová1, Peter Slezák ${ }^{3}$, Jozef Lehotay², \\ Jana Muchová ${ }^{1}$, Carolina Bürki ${ }^{4}$ and Zdeňka Ďuračková ${ }^{1}$ \\ ${ }^{1}$ Institute of Medical Chemistry, Biochemistry and Clinical Biochemistry, Faculty of Medicine, Comenius University, Sasinkova 2, \\ 81108 Bratislava, Slovak Republic \\ ${ }^{2}$ Institute of Analytical Chemistry, Faculty of Chemical and Food Technology, Slovak University of Technology, Radlinského 9, \\ 81237 Bratislava, Slovak Republic \\ ${ }^{3}$ Institute of simulation and virtual medical education, Faculty of Medicine, Comenius University, Sasinkova 4, 81104 \\ Bratislava, Slovak Republic \\ ${ }^{4}$ Horphag Research, Avenue Louis-Casaï 71, 1216 Cointrin/Geneva, Switzerland
}

\begin{abstract}
Oxidative stress reflects an imbalance between antioxidants and pro-oxidants. Many diseases like atherosclerosis or heart failure are involved in oxidative stress. Increased oxidative stress is one of the potential contributing factors to aging. The aim of this study was to monitor the total thiol levels as markers of oxidative stress in 20 healthy volunteers after polyphenols intake (extract from the French oak wood Quercus robur - Robuvit ${ }^{\circledR}$ (300 mg/day)). Polyphenols are known as biomodulators with antioxidant activities. Homocysteine, cysteine and glutathione total levels were determined by using HPLC with electrochemical detection. The activity of the antioxidant enzyme paraoxonase-1 toward two substrates was determined by spectrophotometry. The level of thiol compounds and paraoxonase-1 activities were controlled after run-in (week 0), intervention (week 4) and washout (week 6) period. After the intervention period the results showed that Robuvit ${ }^{\circledR}$ had no significant influence on glutathione level $(p=0.382)$ and paraoxonase activities towards both, arylester and lactone substrates. On the other hand, homocysteine and cysteine levels decreased significantly ( $p=0.029 ; p<0.001$, respectively). The negative correlation between paraoxonase lactonase activity and homocysteine level was noticed. This confirms that paraoxonase might play an important role in homocysteine-thiolactone metabolism.
\end{abstract}

Key words: Ellagitannins - Oxidative stress - Paraoxonase activity - Plasma aminothiols - Quercus robur

\begin{abstract}
Abbreviations: ADMA, asymmetric dimethylarginine; Cys, cysteine; GSH, glutathione; HCy, homocysteine; LOD, limit of detection; LOQ, limit of quantification; PON1, paraoxonase-1; S/N, signal-to-noise.
\end{abstract}

\section{Introduction}

Plasma aminothiols, including homocysteine (HCy), cysteine (Cys) and glutathione (GSH) are investigated as

Correspondence to: Zdeňka Ďuračková, Institute of Medical Chemistry, Biochemistry and Clinical Biochemistry, Faculty of Medicine, Comenius University, Sasinkova 2, 81372 Bratislava, Slovak Republic E-mail: zdenka.durackova@fmed.uniba.sk potential indicators of redox state of the organism and disease risk. Increased plasma HCy is considered as an independent risk factor for cardiovascular disease including atherosclerosis and venous thrombosis. The participation of HCy in cardiovascular risk is not quite understood. HCy seems to cause endothelial dysfunction, induces LDL oxidation and thus leads to the formation of vascular foam cells, while being related with disturbances of blood coagulability (Marinou et al. 2005). 
$\mathrm{HCy}$ is a non-proteinogenic amino acid and was discovered in 1932. It was identified as a product of the essential amino acid methionine (Carmel and Jacobsen 2001). It can be remethylated to methionine or converted to Cys. Plasma HCy level is determined by multiple factors like genetic, demographic, acquired, and lifestyle determinants (Karolczak and Olas 2009). The usual concentration of total HCy reported in several studies of healthy humans varies between 5 and $15 \mu \mathrm{mol} / \mathrm{l}$ (Nekrassova et al. 2003).

Excess of HCy diffuses into the extracellular medium (Chwatko and Bald 2002). HCy is present in the organism in various forms. In the plasma, approximately $70 \%$ of $\mathrm{HCy}$ circulates bound to proteins, $25 \%$ is bonded with itself to form the dimer and less than $5 \%$ is bonded with other thiols, including Cys or is present in 1-2\% in reduced form as thiol. The majority of $\mathrm{HCy}$ is present in oxidized form - mixed disulphide and homocysteine thiolactone (Isobe et al. 2005).

The thioester of homocysteine and HCy-thiolactone play an important role in atherothrombosis. It can form isopeptide bonds with protein lysine residues (homocysteinylation), which alters protein function, activates autoimmune response and enhances thrombosis. All mammals including human have mechanisms for elimination of thiolactone. One such mechanism is a calcium-dependent enzyme associated with HDL-lipoproteins, paraoxonase-1 (PON1), which hydrolyses HCy-thiolactone (Ďuračková and Andrezálová 2009; Jakubowski 2010). PON1 protects proteins against $\mathrm{N}$-homocysteinylation, which is detrimental for protein structure and function and is related to endothelial dysfunction and atherogenesis (Macharia et al. 2012).

The increased level of Cys in physiological fluid such as plasma and urine has recently been recognized as an important indicator for several clinical disorders including cystinosis and cystinuria (Toyo' oka 2009). Cys is a non-essential proteinogenic amino acid involved in protein synthesis and in other metabolic processes of cells. Cys is one of the most abundant plasma thiol and its total plasma concentration is between 200-300 $\mu \mathrm{mol} / \mathrm{l}$ (Rafii et al. 2009). It is a metabolic precursor of reduced glutathione $(\mathrm{GSH})$ - an important "redox buffer" in the organism.

GSH is a tripeptide (L- $\gamma$-glutamyl-L-cysteinyl-glycine) and it is recognized as a key physiological antioxidant that not only detoxifies reactive species directly, but also enhances the functional ability of other crucial antioxidants through their regeneration (ascorbate) or as a co-factor of enzyme glutathione peroxidase. GSH is present in the organism in reduced (GSH) and oxidized (GSSG) form, where the level of GSH is 10-100 times higher than GSSG (Duračková 2014). GSH total level in plasma is about $6 \mu \mathrm{mol} / \mathrm{l}$ (Carmel and Jacobsen 2001; Ďuračková 2010).

The influence of polyphenols on aminothiol levels in human physiological fluids is unclear. The polyphenols in red wine (Chiva-Blanch et al. 2013), in cocoa (Andújar et al. 2012) or in black tea and coffee (Hodgson et al. 2003) did not show a significant influence on plasma HCy level. On the other hand, regular chokeberry juice drinking resulted in reduction of total HCy level (Skoczynska et al. 2007).

The aim of this study was to investigate whether intervention with polyphenolic extract from French oak wood consist namely of roburins, Robuvit ${ }^{\circledR}$ can modify levels of the cardiovascular risk factor, HCy. The other plasma thiols (Cys, GSH) and PON1 activities were also monitored. Roburins are very potent antioxidants (Bazylko et al. 2013; Fracassetti et al. 2013). Humans have been exposed to these polyphenols for centuries from wine and spirits that matured in oak wood barrels. Oak wood is currently the only known source of roburins and according to this specificity, the major source of roburins in human diets results from the consumption of wine and spirits (cognac and whiskey) traditionally matured, aged and stored in oak barrels.

\section{Material and Methods}

\section{Material}

Sodium phosphate monobasic monohydrate, sodium borohydride, perchloric acid, 1-octanesulfonic acid sodium salt, acetonitrile, L-cysteine, L-methionine, L-glutathione reduced and DL-homocysteine were obtained from Sigma Aldrich (Steinheim, Germany), ortho-phosphoric acid, DL-penicillamine from Fluka (Buchs, Switzerland), phenyl acetate and dihydrocoumarin were purchased from Sigma Aldrich (Missouri, USA).

\section{Characteristic of Robuvit ${ }^{\circledR}$}

The French oak wood extract Robuvit ${ }^{\circledR}$ (Horphag Research Ltd.) is a registered proprietary water extract obtained from the wood of Quercus robur. The plant belongs to the plant family Fagacae, genus Quercus. The oak wood contains a specific profile of tannins named roburins that are part of the ellagitannins. Robuvit ${ }^{\circledR}$ is standardized and specified to contain at least $20 \%$ of roburins (A, B, C, D, E) including grandinin. The two most abundant ellagitannins in the Robuvit ${ }^{\circledR}$ are stereoisomers vescalagin and castalagin (Figure 1), which were originally isolated and described by Mayer et al. (1967). Roburins and grandinin are dimers of these compounds or differ by the presence of a pentose substituent. Further to the roburins, Robuvit ${ }^{\circledR}$ contains monomeric vescalagin and castalagin as well as ellagic acid and gallic acid. Robuvit ${ }^{\circledR}$ is bioavailable to humans and its consumption is associated with increase of antioxidant capacity at hydrophilic conditions (Natella et al. 2014). 
Study design and sample

Twenty healthy non-smoking volunteers ( 8 men and 12 women, aged 44-65 year) were included in the study. Volunteers signed informed agreement before the study. The study was approved by the Ethical committee of the Medical Faculty of Comenius University and University hospital, Bratislava.

Volunteers were instructed to control their diet for 2 weeks before the study (run-in period). No additional antioxidants like vitamins $\mathrm{C}$, E or coenzyme $\mathrm{Q}$ or excess of chocolate, red wine and beer were consumed. Drinking a cup of green tea, $2 \mathrm{dl}$ red wine or 0.51 beer daily was allowed. After that polyphenols administration began (week 0 ). Volunteers consumed 1 tablet of polyphenolic extract $(100 \mathrm{mg}$ ) three times a day during 4 weeks (intervention period, week 4) followed by 2 weeks washout period in which tablets were not administrated (week 6).

Level of thiol was measured at the beginning (week 0), on fourth week and sixth week. After clinical investigation (blood pressure, weight, height, body mass index), the biological samples were taken (blood and urine). Baseline characteristics of volunteers are shown in Table 1. During the study baseline characteristics of volunteers were not significantly changed.

Fasting blood samples were collected into vacuum tubes containing ethylene diamine tetraacetic acid (EDTA) as an anticoagulant (1.6 $\mathrm{mg}$ EDTA $/ \mathrm{ml}$ blood) and without an anticoagulant. The samples (serum and plasma) were centrifuged according to the standard protocol $(2500 \times g$ for 5 minutes). After that, they were aliquoted and stored at $-80^{\circ} \mathrm{C}$ until use.

\section{Determination of PON1 activities toward two substrates}

Arylesterase activity of PON1-A: For the determination of PON1 arylesterase activity in serum, phenyl acetate was used as a synthetic substrate. Arylesterase activity was determined according to Gan et al. (1991). Interassay coefficient of variation is $7.1 \%$ and intraassay coefficient of variation is $4.2 \%$.

Lactonase activity of PON1-L: For the measurement of PON1 lactonase activity in serum, dihydrocoumarin was used as a synthetic substrate. Lactonase activity was determined

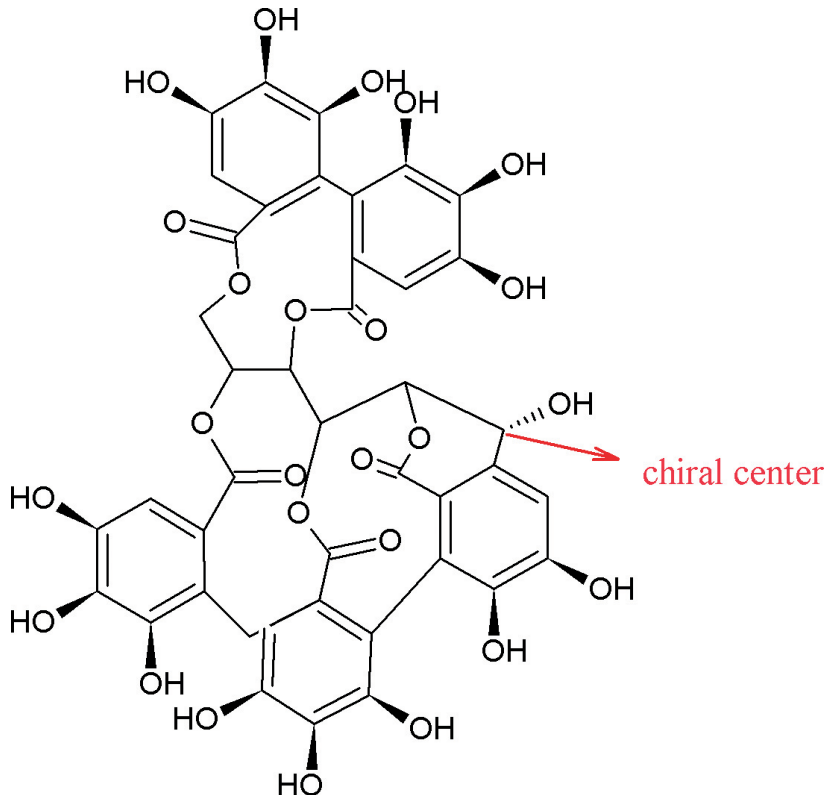

Figure 1. Castalagin as a (33beta)-isomer of vescalagin.

according to Aviram and Rosenblat (2008). Interassay coefficient of variation is $9.5 \%$ and intraassay coefficient of variation is $2 \%$.

\section{Determination of thiol samples}

Samples for analyzing of thiols (Cys, HCy and GSH) concentration in plasma by HPLC system were pre-treated according to Garaiova et al. (2013). A mixture of $100 \mu \mathrm{l}$ of plasma, $50 \mu \mathrm{l}$ internal standards and $40 \mu \mathrm{l}$ sodium borohydride was incubated for 30 minutes at $50^{\circ} \mathrm{C}$ to reduce and release protein-bound thiols, after which $100 \mu$ l perchloric acid was added to deproteination. After the sample centrifugation for 5 minutes at $14000 \times g$ the supernatant was diluted 1:1 with the mobile phase. $20 \mu \mathrm{l}$ of this mixture was injected into a column.

The chromatographic system consisted of an isocratic pump (DeltaChrom SDS 030, Watrex, Praha, Czech Republic) and automatic injector (Autosampler Basic-Marathon type 816, Spark Holland, Emmen, Netherlands). Separation

Table 1. Baseline characteristics of volunteers

\begin{tabular}{lcccc}
\hline & Age (years) & Height $(\mathrm{m})$ & Weight $(\mathrm{kg})$ & BMI $\left(\mathrm{kg} / \mathrm{m}^{2}\right)$ \\
\hline All & $54.2 \pm 6.5$ & $1.70 \pm 0.09$ & $82.9 \pm 19.4$ & $28.4 \pm 5.1$ \\
$\mathrm{~F}(n=12)$ & $53.0 \pm 7.7$ & $1.64 \pm 0.05$ & $74.2 \pm 16.9$ & $27.4 \pm 5.4$ \\
$\mathrm{M}(n=8)$ & $55.9 \pm 4.3$ & $1.79 \pm 0.07$ & $95.8 \pm 15.8$ & $29.9 \pm 4.4$ \\
\hline
\end{tabular}

Data are presented as mean \pm SD. $n$, number of volunteers; F, female; M, male; BMI, body mass index. 
was performed on Purosher RP-18 250-4 (5 $\mu \mathrm{m})$ (Merck, Darmstadt, Germany). The mobile phase $(0.8 \mathrm{ml} / \mathrm{min})$ was composed of $50 \mathrm{mmol} / \mathrm{l}$ phosphate buffer, $1 \mathrm{mmol} / \mathrm{l}$ octanesulfonic acid ( $\mathrm{pH}$ 2.7) and acetonitrile (94:6 v/v) mixture. Aminothiols were detected by electrochemical detection (Coulochem II, ESA, Chelmsford, UK) composed of guard cell Model 5020 and analytical cell Model 5010A (ESA, Chelmsford, UK). DL-penicillamine was used as an internal standard. The response of amino acids was compared to response of internal standard. All samples were measured in triplicates.

\section{Statistical analysis}

Data were analyzed using StatsDirect statistical software (http://www.statsdirect.com, England: StatsDirect Ltd. 2008) and MS Excel 2010. Difference among glutathione and homocysteine at different time points where analyzed by Friedman test followed by all pairwise comparisons due to Conover. Correlation between two continuous variables was assessed using Pearson's correlation coefficient $r$. Simultaneous effect of age and gender on effect of treatment (difference between level of measured markers at week 0 and week 4) was analysed using multiple linear regression. All analyses were performed at level of significance 5\%. The limits of detection (LOD) and quantification (LOQ) were defined as the concentrations for which the signal-to-noise $(\mathrm{S} / \mathrm{N})$ ratios were 3 and 10 , respectively.

\section{Results}

In this work, the influence of Robuvit ${ }^{\circledR}$ on HCy, Cys and GSH total levels was considered. Their concentrations were monitored after run-in period (week 0), after 4 weeks Robuvit ${ }^{\circledR}$ intake (week 4) and after 2 weeks washout period (week 6). After 4 weeks of extract intake, the French oak wood extract had no significant influence on GSH levels $(p=0.382)$. On the other hand, Cys $(p<0.001)$ and HCy $(p=0.029)$ levels were significantly decreased (Table 2 ). No significant effect of gender was reported for all monitored amino acids. The level of HCy in women was decreased by $2.4 \mu \mathrm{mol} / \mathrm{l}$ ( $p=$ $0.055)$ in comparison to men, where reduced HCy levels by $0.6 \mu \mathrm{mol} / \mathrm{l}(p=0.640)$. This gender dependence remains inconclusive.

The level of HCy is dependent on age $(r=0.52, p<0.010)$ and also the effect of treatment on the HCy level significantly depended on age (Figure 2$)(p=0.009)$. It means that older individuals are more sensitive to treatment with higher reduction of HCy level. During the washout period the levels of HCy, Cys and GSH significantly increased again ( $p=0.008, p<0.001$ and $p=0.002$, respectively) to almost initial levels (Table 2).

The calibration curves of amino acid standards indicated high linearity $\left(r^{2}>0.99\right)$ (not shown). The LOD and LOQ at S/N of 3 and 10 for HCy, GSH and Cys were 0.166, 0.173 and $0.484 \mu \mathrm{mol} / \mathrm{l}$ and $0.553,0.577$ and $1.612 \mu \mathrm{mol} / \mathrm{l}$, respectively.

Table 2. Comparison of differences in plasma thiol levels after run-in (week 0), intervention (week 4) and washout (week 6) period

\begin{tabular}{|c|c|c|c|c|c|c|}
\hline & & week 0 & week 4 & $p^{\mathrm{a}}$ & week 6 & $p^{\mathrm{b}}$ \\
\hline \multirow{3}{*}{ cysteine } & all & $305.6 \pm 49.1$ & $220.7 \pm 34.5$ & $<0.001$ & $276.1 \pm 56.6$ & $<0.001$ \\
\hline & $\mathrm{F}$ & $311.1 \pm 42.6$ & $236.1 \pm 28.0$ & $<0.001$ & $287.7 \pm 52.9$ & 0.014 \\
\hline & $\mathrm{M}$ & $297.3 \pm 52.6$ & $197.5 \pm 31.4$ & $<0.001$ & $258.7 \pm 61.0$ & 0.006 \\
\hline \multirow{3}{*}{ glutathione } & all & $17.0 \pm 5.5$ & $16.4 \pm 5.0$ & n. s. & $20.4 \pm 3.6$ & 0.002 \\
\hline & $\mathrm{F}$ & $18.4 \pm 5.3$ & $17.7 \pm 5.2$ & n. s. & $20.3 \pm 4.4$ & n. s. \\
\hline & $\mathrm{M}$ & $14.9 \pm 5.2$ & $14.4 \pm 4.0$ & n. s. & $20.7 \pm 2.0$ & 0.006 \\
\hline \multirow{3}{*}{ homocysteine } & all & $10.35 \pm 4.3$ & $8.43 \pm 2.6$ & 0.029 & $9.65 \pm 2.9$ & 0.004 \\
\hline & $\mathrm{F}$ & $9.7 \pm 4.3$ & $7.3 \pm 1.9$ & 0.055 & $8.7 \pm 2.4$ & 0.03 \\
\hline & M & $11.0 \pm 4.6$ & $9.9 \pm 2.7$ & n. s. & $10.7 \pm 3.5$ & 0.09 \\
\hline \multirow{3}{*}{ PON1-A } & all & $115.8 \pm 30.3$ & $116.7 \pm 29.2$ & n. s. & $116.8 \pm 31.3$ & n. s. \\
\hline & $\mathrm{F}$ & $119.8 \pm 25.4$ & $119.7 \pm 23.9$ & n. s. & $119.0 \pm 23.9$ & n. s. \\
\hline & M & $109.8 \pm 37.7$ & $112.1 \pm 36.9$ & n. s. & $113.4 \pm 41.7$ & n. s. \\
\hline \multirow{3}{*}{ PON1-L } & all & $12.3 \pm 2.7$ & $12.0 \pm 2.7$ & n. s. & $12.0 \pm 2.6$ & n.s. \\
\hline & $\mathrm{F}$ & $12.8 \pm 2.6$ & $12.5 \pm 2.6$ & n. s. & $12.6 \pm 2.2$ & n.s. \\
\hline & M & $11.4 \pm 2.8$ & $11.1 \pm 2.7$ & n. s. & $11.2 \pm 3.0$ & n. s. \\
\hline
\end{tabular}

Thiols data (in $\mu \mathrm{mol} / \mathrm{l})$ are shown as an average of total concentrations $\pm \mathrm{SD}$. F, female $(n=12)$; M, male $(n=8) ; n$, number of volunteers; n. s., not significant ( $p>0.050)$; PON1-A, paraoxonase-1 towards phenylacetate as a substrate; PON1-L, paraoxonase-1 towards dihydrocoumarin as a substrate; PON1-A and PON1-L data are shown as an average of the activity $(\mathrm{U} / \mathrm{ml}) \pm \mathrm{SD} .{ }^{\mathrm{a}}$ week 0 versus week 4 , b week 4 versus week 6. 
We investigated activity of PON1 on its arylesterase and lactonase activities (Table 2). The extract administration had no significant influence on PON1-A and PON1-L activities in human serum.

\section{Discussion}

The influence of French oak wood extract on total thiol levels was monitored. The level of Cys significantly decreased. We can only hypothesize that Cys is rather converted to degraded products like taurine or sulfate than be involved as a precursor for GSH synthesis. We did not notice a significant change in GSH level during intervention period. HCy level were significantly decreased. Chen et al. (2012) describe in their work that HCy has an indirect effect on synthesis of asymmetric dimethylarginine (ADMA). HCy can inhibit the enzyme that metabolizes ADMA. It also increases synthesis of ADMA by activating the endoplasmic reticulum stress pathway (Perna et al. 2010). Both HCy and ADMA are thought to mediate their adverse vascular effects (van Guldener et al. 2007) and we assume that decrease HCy level has positive influence also on ADMA level (not shown).

Older volunteers were more sensitive to Robuvit ${ }^{\circledR}$. No significant effect of gender was reported. On the other hand, the effect of treatment (defined as difference between values of homocysteine at week 0 and week 4) positively depended on age $(p=0.009)$ and tended to a better response among women $(p=0.055)$, however, this remains inconclusive.

There are no known human studies on the effect of ellagitannins on HCy level. Only Kannan and Quine (2011) found that pretreatment with the basic component of ellagitannins, ellagic acid, prevents isoproterenol-induced oxidative stress and decreased HCy level in myocardial infarction in rats. In a number of other human studies some positive effects were found on markers of oxidative stress (increased activity of PON1, reduced TBARP in serum, reduced 8-oxo-dG level) or on lipid profile (Aviram et al. 2000; Cerdá et al. 2004; Pantuck et al. 2006; Heber et al. 2007; Rock et al. 2008; Fuhrman et al. 2010; Larrosa et al. 2010; López-Uriarte et al. 2010). Positive effects were not observed after ellagic acid or ellagitanins supplementation on inflammatory markers (IL-6 and CRP) (Trombold et al. 2010) and on cholesterol level in subjects with metabolic syndrome (Casas-Agustench et al. 2010). Among natural substances containing other polyphenols belongs to example cranberry juice containing namely anthocyanidins, cyanidins, peonidins and quercetin. Cranberry juice consumption did not significantly alter GSH and HCy levels in comparison to placebo (Duthie et al. 2006).

Results showed that the oak wood extract Robuvit ${ }^{\circledR}$ administration had no significant influence on paraoxonase activities towards both, arylester and lactone substrates and GSH level as well. It is in contradiction with result of Rock et al. (2008) who found enhancement of PON1 arylesterase, paraoxonase and lactonase activities. Similarly, Aviram et al. (2000) observed increased PON1 arylesterase activity after pomegranate juice consumption (tannins and anthocyanins). We assumed that these differences could be caused by application of different polyphenols treatment. Although, we did not observe increased activity of PON1, negative correlation between PON1-L activity and HCy level was noticed after intervention period (Figure 3). This confirms

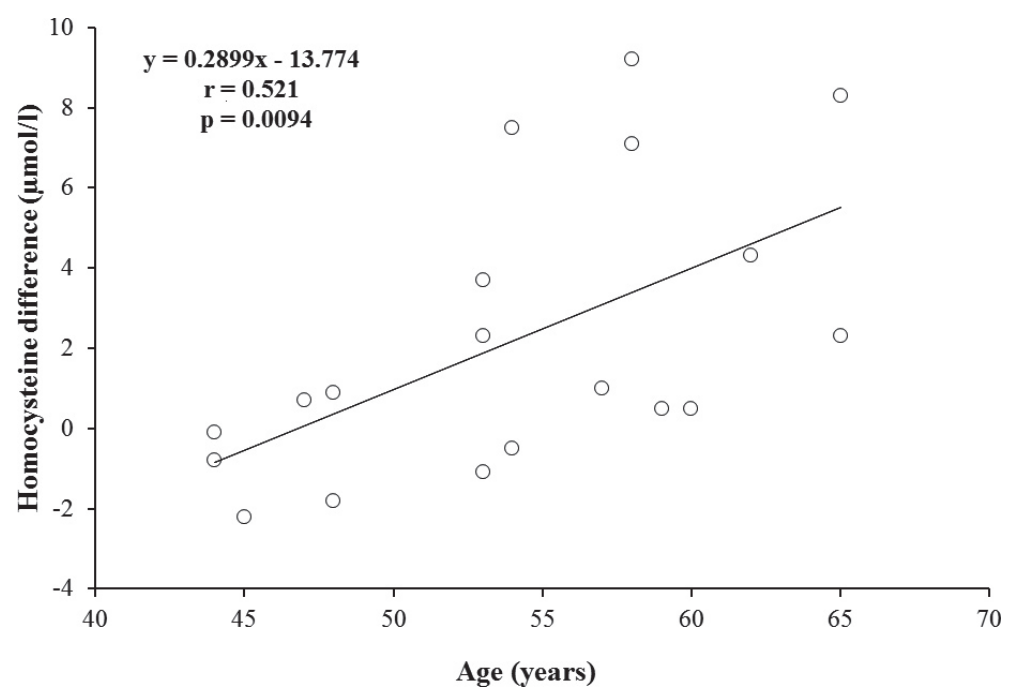

Figure 2. Regression analysis between polyphenols treatment (difference between homocysteine concentrations before and after intervention period) and volunteer's age. 


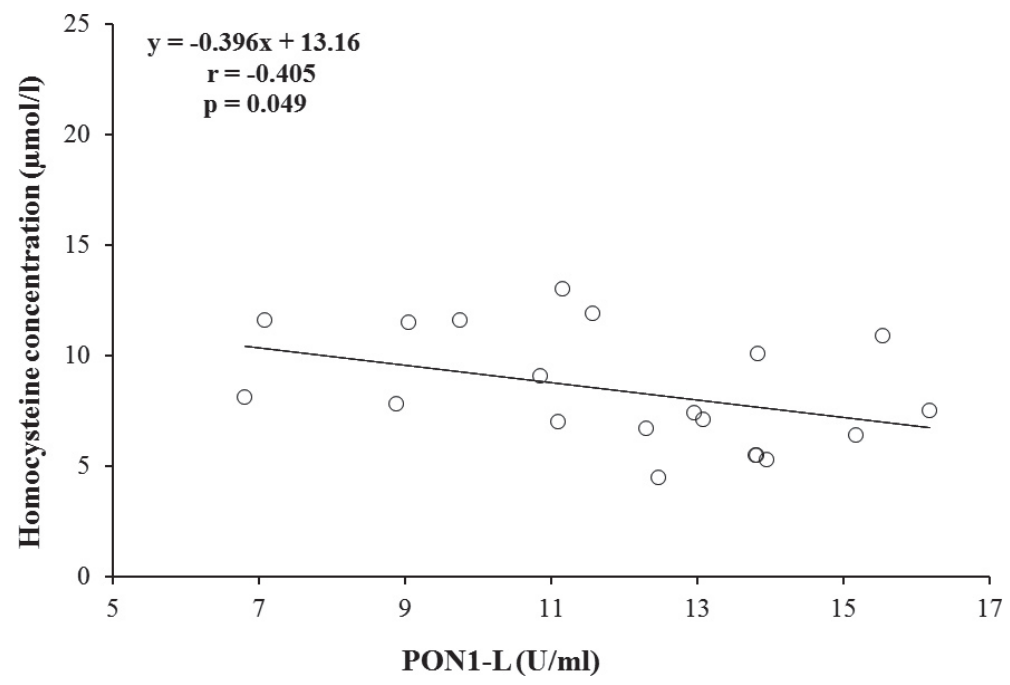

Figure 3. Correlation between homocysteine concentration and PON1-L activity after 4 weeks of polyphenols administration.

that PON1 might play an important role in HCy-thiolactone metabolism (Perla-Kaján and Jakubowski 2012).

\section{Conclusion}

Robuvit ${ }^{\circledR}$ had no significant influence on glutathione level and paraoxonase activities towards both, arylester and lactone substrates. On the other hand, homocysteine and cysteine levels decreased significantly.

Acknowledgements. The authors would like to thank all the patients and clinical staff who took part in this study. This study was partially supported by grants KEGA 003UK-4/201, VEGA 1/0499/14, Mind and Health, civil association; Robuvit ${ }^{\circledR}$ was obtained from Horphag Research Ltd.

Conflict of interest. The authors declare that there are no conflicts of interest.

\section{References}

Andújar I., Recio M. C., Ríos J. L. (2012): Cocoa polyphenols and their potential benefits for human health. Oxid. Med. Cell. Longev. 2012, 1-23 http://dx.doi.org/10.1155/2012/906252

Aviram M., Dornfeld L., Rosenblat M., Volkova N., Kaplan M., Coleman R., Hayek T., Presser D., Fuhrman B. (2000): Pomegranate juice consumption reduces oxidative stress, atherogenic modifications to LDL, and platelet aggregation: studies in humans and in atherosclerotic apolipoprotein E-deficient mice. Am. J. Clin. Nutr. 1, 1062-1076

Aviram M., Rosenblat M. (2008): Paraoxonases (PON1, PON2, PON3) analyses in vitro and in vivo in relation to cardiovascular diseases. Methods Mol. Biol. 477, 259-276 http://dx.doi.org/10.1007/978-1-60327-517-0_20

Bazylko A., Piwowarski J. P., Filipek A., Bonarewicz J., Tomczyk M. (2013): In vitro antioxidant and anti-inflammatory activities of extracts from Potentilla recta and its main ellagitannin, agrimoniin. J. Ethnopharmacol. 149, 222-227 http://dx.doi.org/10.1016/j.jep.2013.06.026

Carmel R., Jacobsen D. W. (2001): Homocysteine in Health and Disease. Cambridge University Press, United Kingdom

Casas-Agustench P., Bulló M., Salas-Salvadó J. (2010): Nuts, inflammation and insulin resistance. Asia Pac. J. Clin. Nutr. 19, 124-130

Cerdá B., Espín J. C., Parra S., Martínez P., Tomás-Barberán F. A. (2004): The potent in vitro antioxidant elagitannins from pomegranate juice are metabolised into bioavailable but poor antioxidant hydroxyl-6H-dibenzopyran-6-one derivatives by the colonic microflora of healthy humans. Eur. J. Nutr. 43, 205-220 http://dx.doi.org/10.1007/s00394-004-0461-7

Chen S., Li N., Deb-Chatterji M., Dong Q., Kielstein J. T., Weissenborn K., Worthmann H. (2012): Asymmetric dimethyarginine as marker and mediator in ischemic stroke. Review. Int. J. Mol. Sci. 13, 15983-16004 http://dx.doi.org/10.3390/ijms131215983

Chiva-Blanch G., Urpi-Sarda M., Ros E., Valderas-Martinez P., Casas R., Arranz S., Guillén M., Lamuela-Raventós R. M., Llorach R., Andres-Lacueva C., Estruch R. (2013): Effects of red wine polyphenols and alcohol on glucose metabolism and the lipid profile: A randomized clinical trial. Clin. Nutr. 32, 200-206 http://dx.doi.org/10.1016/j.clnu.2012.08.022

Chwatko G., Bald E. (2002): Determination of different species of homocysteine in human plasma by high-performance liquid chromatography with ultraviolet detection. J. Chromatogr. A 949, 141-151 http://dx.doi.org/10.1016/S0021-9673(01)01343-7

Duthie S. J., Jenkinson A. M., Crozier A., Mullen W., Pirie L., Kyle J., Yap L. S., Christen P., Duthie G. G. (2006): The effects of 
cranberry juice consumption on antioxidant status and biomarkers relating to heart disease and cancer in healthy human volunteers. Eur. J. Nutr. 45, 113-122 http://dx.doi.org/10.1007/s00394-005-0572-9

Duračková Z., Andrezálová L. (2009): Paraoxonase and atherosclerosis. Klin. Biochem. Metab. 17, 220-226 (in Slovak)

Duračková Z. (2010): Some current insights into oxidative stress. Physiol. Res. 59, 459-469

Ďuračková Z. (2014): Free radicals and antioxidants for nonexperts. In: Laher I.: Systems Biology of Free Radicals and Antioxidants. pp. 3-38, Springer, Heilderberg

Fracassetti D., Costa C., Moulay L., Tomás-Barberán F. A. (2013): Ellagic acid derivatives, ellagitannins, proanthocyanidins and other phenolics, vitamin $\mathrm{C}$ and antioxidant capacity of two powder products from camu-camu fruit (Myrciaria dubia). Food Chem. 139, 578-588 http://dx.doi.org/10.1016/j.foodchem.2013.01.121

Fuhrman B., Volkova N., Aviram M. (2010): Pomegranate juice polyphenols increase recombinant paraoxonase-1 binding to high-density lipoprotein: studies in vitro and in diabetic patients. Nutrition 26, 359-366 http://dx.doi.org/10.1016/j.nut.2009.05.003

Gan K. N., Smolen A., Eckerson H. W., La Du B. N. (1991): Purification of human serum paraoxonase/arylesterase. Evidence for one esterase catalyzing both activities. Drug Metab. Dispos. 19, 100-106

Garaiova I., Muchová J., Nagyová Z., Mišlanová C., Oravec S., Dukát A., Wang D., Plummer S. F., Duuračková Z. (2013): Effect of a plant sterol, fish oil and B vitamin combination on cardiovascular risk factors in hypercholesterolemic children and adolescents: a pilot study. Nutr. J. 12, 1-8 http://dx.doi.org/10.1186/1475-2891-12-7

Heber D., Seeram N. P., Wyatt H., Henning S. M., Zhang Y., Ogden L. G., Dreher M., Hill J. O. (2007): Safety and antioxidant activity of a pomegranate ellagitannin-enriched polyphenol dietary supplement in overweight individuals with increased waist size. J. Agric. Food Chem. 55, 10050-10054 http://dx.doi.org/10.1021/jf071689v

Hodgson J. M., Burke V., Beilin L. J., Croft K. D., Puddey I. B. (2003): Can black tea influence plasma total homocysteine concentrations. Am. J. Clin. Nutr. 77, 907-911

Isobe Ch., Murata T., Sato Ch., Terayama Y. (2005): Increase of total homocysteine concentration in cerebrospinal fluid in patients with Alzheimer's disease and Parkinson's disease. Life Sci. 77, 1836-1843 http://dx.doi.org/10.1016/j.lfs.2005.02.014

Jakubowski H. (2010): The role of paraoxonase 1 in the detoxification of homocysteine thiolactone. Adv. Exp. Med. Biol. 66, $113-127$ http://dx.doi.org/10.1007/978-1-60761-350-3_11

Kannan M. M., Quine S. D. (2011): Ellagic acid ameliorates isoproterenol induced oxidative stress: Evidence from electrocardiological, biochemical and histological study. Eur. J. Pharmacol. $659,45-52$ http://dx.doi.org/10.1016/j.ejphar.2011.02.037

Karolczak K., Olas B. (2009): Mechanism of action of homocysteine and its thiolactone in hemostasis system. Physiol. Res. 58, 623-633
Larrosa M., Garcia-Conesa M. T., Espín J. C., Tomás-Barberán F. A. (2010): Ellagitannins, ellagic acid and vascular health. Mol. Aspects Med. 31, 513-539 http://dx.doi.org/10.1016/j.mam.2010.09.005

López-Uriarte P., Nogués R., Saez G., Bulló M., Romeu M., Masana L., Tormos C., Casas-Agustench P., Salas-Salvadó J. (2010): Effect of nut consumption on oxidative stress and the endothelial function in metabolic syndrome. Clin Nutr. 29, 373-380 http://dx.doi.org/10.1016/j.clnu.2009.12.008

Macharia M., Hassan M. S., Blackhurst D., Erasmus R. T., Matsha T. E. (2012): The growing importance of PON in cardiovascular health: review. J. Cardiovasc. Med. 13, 443-453 http://dx.doi.org/10.2459/JCM.0b013e328354e3ac

Marinou K., Antoniades Ch., Tousoulis D., Pitsavos Ch., Goumas G., Stefanadis Ch. (2005): Homocysteine: a risk factor for coronary artery disease? Hellenic. J. Cardiol. 46, 59-67

Mayer W., Gabler W., Riester A., Korger H. (1967): On tannins compounds from the wood of chestnut and oak wood-IIs. Isolation of castalagin, vescalagin, castalin and vescaline. Liebigs Ann. Chem. 707, 177-181 http://dx.doi.org/10.1002/jlac.19677070125

Natella F., Leoni G., Maldini M., Natarelli L., Comitato R., Schonlau F., Virgili F., Canali R. (2014): Absorption, metabolism, and effects at transcriptome level of a standardized French oak wood extract, Robuvit, in healthy volunteers: pilot study. J. Agric. Food Chem. 62, 443-453 http://dx.doi.org/10.1021/jf403493a

Nekrassova O., Lawrence N. S., Compton R. G. (2003): Analytical determination of homocysteine (review). Talanta 60, 1085-1095 http://dx.doi.org/10.1016/S0039-9140(03)00173-5

Pantuck A. J., Leppert J. T., Zomoridian N., Aronson W., Hong J., Barnard R. J., Seeram N. P., Liker H., Wang H. J., Elashoff R., Heber D., Aviram M., Ignarro L., Belldegrun A. (2006): Phase II study of pomegranate juice for men with rising prostate-specific antigen following surgery or radiation for prostate cancer. Clin. Cancer Res. 12, 4018-4026 http://dx.doi.org/10.1158/1078-0432.CCR-05-2290

Perla-Kaján J., Jakubowski H. (2012): Paraoxonase 1 and homocysteine metabolism. Amino Acids 43, 1405-1417 http://dx.doi.org/10.1007/s00726-012-1321-z

Perna M., Roman M. J., Alpert D. R., Crow M. K., Lockshin M. D., Sammaritano L., Devereux R. B., Cooke J. P., Salmon J. E. (2010): Relationship of asymmetric dimethylarginine and homocysteine to vascular aging in systemic lupus erythematosus patients. Arthritis and Rheumatism 62, 1718-1722 http://dx.doi.org/10.1002/art.27392

Rafii M., Elango R., House J. D., Courtney-Martina G., Darling P., Fisher L., Pencharz P.B. (2009): Measurement of homocysteine and related metabolites in human plasma an urine by liquid chromatography electrospray tandem mass spectrometry. J. Chromatogr. B 877, 3282-3291 http://dx.doi.org/10.1016/j.jchromb.2009.05.002

Rock W., Rosenblat M., Miller-Lotan R., Levy A. P., Elias M., Aviram M. (2008): Consumption of wonderful variety pomegranate juice and extract by diabetic patients increases paraoxonase 1 association with high-density lipoprotein and stimulates its catalytic activities. J. Agric. Food Chem. 56, 8704-8713 http://dx.doi.org/10.1021/jf801756x 
Skoczynska A., Jêdrychowska I., Porêba R., Affelska-Jercha A., Turczyn B., Wojakowska A., Andrzejak R. (2007): Influence of chokeberry juice on arterial blood pressure and lipid parameters in men with mild hypercholesterolemia. Pharmacolog. Reports 59, 177-182

Toyooka T. (2009): Recent advances in separation and detection methods for thiol compounds in biological samples. J. Chromatogr. B 877, 3318-3330 http://dx.doi.org/10.1016/j.jchromb.2009.03.034

Trombold J. R., Barnes J. N., Critchley L., Coyle E. F. (2010): Ellagitannin consumption improves strength recovery $2-3 \mathrm{~d}$ after eccentric exercise. Med. Sci. Sports. Exerc. 42, 493-498
http://dx.doi.org/10.1249/MSS.0b013e3181b64edd

van Guldener C., Nanayakkara P. W. B., Stehouwer C. D. A. (2007):

Homocysteine and asymmetric dimethylarginine (ADMA): biochemically linked but differently related to vascular disease in chronic kidney disease. Clin. Chem. Lab. Med. 45, $1683-1687$

http://dx.doi.org/10.1515/CCLM.2007.340

Received: June 23, 2014

Final version accepted: August 31, 2014

First published online: November 4, 2014 